\title{
La Respuesta de República Dominicana en TIEMPOS DE la COVID-19: MEDIDAS IMPLEMENTADAS
}

\author{
Aida Mary Camacho Peña ${ }^{a}$, Chaly Nicole Cruz Pozo ${ }^{b}$, Kelvin B. \\ Rodriguez ${ }^{c}$, Miguel De La Rosa ${ }^{\text {d, Rosa M. De La Cruz Yeb }}{ }^{\mathrm{e}}$ \\ y Yury MaYcar Mejía Barros ${ }^{\mathrm{f}}$
}

Recibido: 9/7/2020 • Aprobado: 1/9/2020

Cómo citar: Camacho Peña, A. M, Cruz Pozo, C.N., B. Rodríguez, K., De La Rosa, M., de La Cruz Yeb, R.M. \& Mejía Barros, Y.M. (2020). La respuesta de República Dominicana en tiempos de la Covid-19: medidas implementadas. Ciencia, Economía y Negocios, 4(2), 87-106. Doi: https://doi.org/10.22206/ ceyn.2020.v4i2. 87-106

\begin{abstract}
Resumen
Este artículo expone una visión global de las medidas implementadas en la República Dominicana ante la crisis de la COVID-19. Detalla las iniciativas tributarias y socioeconómicas, que han facilitado el cumplimiento tributario y reducen los efectos negativos de la paralización económica a raiz del estado de emergencia nacional, tanto para las empresas como para los ciudadanos. Se presenta un análisis integral alusivo a, prescripciones; cobro de impuestos; aplazamientos de pagos; control y fiscalización; recaudaciones tributarias, y trámites electrónicos. Asimismo se estudia el efecto sobre Economía Digital, Factura Electrónica (e-CF) y Precios de Transferencia. Finalmente se revisa la propuesta de actualidad tributaria en el país.
\end{abstract}

Palabras clave: COVID-19; cumplimiento tributario; medidas tributarias; programas sociales; economía digital.

\footnotetext{
a Instituto Tecnológico de Santo Domingo y Dirección General de Impuestos Internos, Santo Domingo, República Dominicana. ORCID: 0000-0002-4516-1866

Correo-e: dcpymec18@gmail.com

b Pontificia Universidad Católica Madre y Maestra y Dirección General de Impuestos Internos, Santo Domingo, República Dominicana, ORCID: 0000-0002-0881-600

Correo: chalycruz@gmail.com

c Dirección General de Impuestos Internos, Santo Domingo, República Dominicana. ORCID: 0000-0001-9588-6104, Correo-e: rodriguezkelvin22@gmail.com

d Dirección General de Impuestos Internos, Santo Domingo, República Dominicana. ORCID: 0000-0003-17923437. Correo-e: ang.delarosa@gmail.com

${ }^{\mathrm{e}}$ Ministerio de Hacienda de la República Dominicana, Santo Domingo, República Dominicana. ORCID: 0000-0003-22434689,Correo-e: rosamaría.dlcyeb@hotmail.com

${ }^{\mathrm{f}}$ KPMG Américas y Pontificia Universidad Católica Madre y Maestra. ORCID: 0000-00027358-4153, Correo-e: yurymmb@gmail.com
} 


\title{
The response of Dominican Republic in Covid-19's times: IMPLEMENTED MEASURES
}

\section{Aida Mary Camacho Peńa, Chaly Nicole Cruz Pozo, Kelvin B. Rodriguez, Miguel De La Rosa, Rosa M. De La Cruz Yeb y Yury Maycar Mejía Barros}

Received: 9/7/2020 Approved: 1/9/2020

\begin{abstract}
This article presents a global vision of the measures implemented in the Dominican Republic in the face of the COVID-19 crisis. It details the tax and socio-economic initiatives that facilitate tax compliance and reduces the negative effects of economic paralysis as a result of the national state of emergency, for business and also citizens. A comprehensive analysis is presented, alluding to; tax collection; deferments of payments; tax collections, and electronic procedures. The effect on Digital Economy, Electronic Invoice (e-CF) and Transfer Prices is also studied. Finally, it reviews the topics of tax novelty in the country.
\end{abstract}

Keywords; COVID-19; Tax Compliance; Electronic Invoice; Social Programs; Digital Economy. 


\section{Introducción}

Con motivo de la crisis internacional, desatada por la pandemia, de la COVID-19, el Gobierno de la República Dominicana, viendo cómo la crisis ha afectado significativamente los sectores salud, economía y sociedad en general, ha implementado una serie de medidas tributarias y sociales, como una forma de apoyar a los contribuyentes en medio de la crisis, y a futuro permitir, no solo la recuperación del tejido productivo del país y del bienestar económico de los dominicanos, sino también la consolidación del desarrollo del país para hacerle frente a la crisis que se avecina.

En vista de la situación económica que se está enfrentando en el país, el Poder Ejecutivo declaró el territorio nacional un primer Estado de Emergencia el pasado 19 de marzo, el cual fue prorrogado hasta el 1ro. de julio. Recientemente, se ha declarado un nuevo Estado de emergencia por un período de 45 días a partir del 20 de julio de 2020, debido a la evolución epidemiológica del referido virus. En consecuencia, en el presente documento procuramos exponer las medidas implementadas en el período comprendido desde el 19 de marzo hasta el 1ro. de julio, describiendo y llevando un análisis que trascienda el aspecto puntual de las $m$ tocando temas novedad tributaria a nivel local e internacional como economía digital, facturación electrónica, precios de transferencia, entre otros.

Las opiniones expresadas en el presente artículos son producto del consenso de los autores y no representan la posición de la Administración Tributaria (DGII), ni de ninguna institución pública o privada.

\section{Medidas tributarias}

\section{Prescripciones}

Ante la declaración del estado de emergencia, el Poder Ejecutivo, con el fin de garantizar los derechos de las contribuyentes y resguardar los plazos y los términos que rigen los procedimientos administrativos que se desarrollan en la Administración Tributaria, emitió por decreto la suspensión del cómputo de algunos plazos mediante el Decreto núm. 137-20 (Presidente de la República, 2020). 
A tales fines, la referida disposición indica que:

"Con eficacia retroactiva al viernes 20 de marzo de 2020, y mientras dure la vigencia del estado de emergencia, se suspende el cómputo de los plazos y términos de los procedimientos administrativos instrumentados ante los organismos públicos (...), incluyendo los plazos para la interposición de recursos administrativos, los plazos de prescripción y caducidad, asi como cualquier plazo otorgado por estos organismos en ocasión de procedimientos administrativos en curso" (Decreto 137-20, 2020).

El siguiente esquema ilustra de forma resumida las medidas de carácter prescriptivo.

1.1 Suspendió el cómputo de los plazos para la interposición de recursos administrativos, los plazos de prescripción y cualquier otro plazo otorgado en DGII, sobre procedimientos administrativos ya en curso.

1.2 Suspensión de los plazos referidos no exime a los contribuyentes del cumplimiento de los deberes formales y obligaciones tributarias.

2. Consejo del Poder Judicial, mediante Acta núm. 02-2020, de fecha 19 de marzo de 2020 dispuso la suspensión de los plazos procesales.

3. Tribunal Constitucional, estableció mediante la Resolución núm. TC 0002/20, de fecha 20 de marzo de 2020, la suspensión de los plazos, para cualquiera de las actuaciones procesales.

4. Los plazos establecidos fueron reanudados tres (3) días hábiles después del cese del estado de emergencia, levantado mediante el Decreto núm. 237-20, de fecha 1ero. de julio de 2020 .

\section{Cobro de impuestos y aplazamientos de pago}

Durante el tiempo de crisis por la pandemia COVID-19, la Administración Tributaria ha implementado una serie de acciones encami- 
nadas a facilitar la declaración y pago de las obligaciones fiscales de los contribuyentes, las cuales se exponen a continuación:

\section{A. Aplazamientos de pago y/o prórrogas en las declaraciones}

En los siguientes cuadros se muestran las obligaciones fiscales que han sido prorrogadas, tanto en la fecha de presentación como de pago correspondiente, producto de las medidas administrativas ejecutadas por la Dirección General de Impuestos Internos (DGII) ${ }^{1}$ a través de los avisos publicados:

\section{Prórrogas en Declaraciones de Impuestos}

\begin{tabular}{|c|c|c|c|}
\hline Obligaciones Fiscales & Fecha límite normal & Nueva fecha límite & Prórroga en días \\
\hline ISR - Personas Jurídicas con cierre 122019 & $29 / 4 / 2020$ & $29 / 7 / 2020$ & 91 \\
\hline ISR - Personas Jurídicas con cierre 032020 & $29 / 7 / 2020$ & $31 / 8 / 2020$ & 33 \\
\hline ISR - Personas Físicas & $30 / 3 / 2020$ & $29 / 7 / 2020$ & 121 \\
\hline Declaración Jurada ISR PF con negocios único dueño & $29 / 4 / 2020$ & $29 / 7 / 2020$ & 91 \\
\hline ITBIS 022020 & $20 / 3 / 2020$ & $30 / 3 / 2020$ & 10 \\
\hline Otras Retenciones y Retribuciones Complementarias & $13 / 4 / 2020$ & $24 / 4 / 2020$ & 11 \\
\hline Impuesto a los hidrocarburos IH4 032020 & $9 / 4 / 2020$ & $23 / 4 / 2020$ & 14 \\
\hline Contribución GLP Semanal & $9 / 4 / 2020$ & $23 / 4 / 2020$ & 14 \\
\hline Impuesto a los hidrocarburos IH1 042020 & $16 / 4 / 2020$ & $23 / 4 / 2020$ & 7 \\
\hline Contribución GLP Semanal & $16 / 4 / 2020$ & $23 / 4 / 2020$ & 7 \\
\hline Impuesto a los hidrocarburos IH2 042020 & $23 / 4 / 2020$ & $30 / 4 / 2020$ & 7 \\
\hline Contribución GLP Semanal & $23 / 4 / 2020$ & $30 / 4 / 2020$ & 7 \\
\hline Impuesto a bancas deportivas 032020 & $22 / 4 / 2020$ & $22 / 7 / 2020$ & 91 \\
\hline Impuesto a bancas de lotería 032020 & $22 / 4 / 2020$ & $22 / 7 / 2020$ & 91 \\
\hline Impuesto a bancas deportivas 042020 & $22 / 5 / 2020$ & $24 / 8 / 2020$ & 94 \\
\hline Impuesto a bancas de lotería 042020 & $22 / 5 / 2020$ & $24 / 8 / 2020$ & 94 \\
\hline Impuesto a bancas deportivas 052020 & $22 / 6 / 2020$ & $22 / 9 / 2020$ & 92 \\
\hline Impuesto a bancas de lotería 052020 & $22 / 6 / 2020$ & $22 / 9 / 2020$ & 92 \\
\hline Impuesto sobre Casinos de Juego 042020 & $5 / 5 / 2020$ & $5 / 8 / 2020$ & 92 \\
\hline Impuesto sobre máquinas tragamonedas 042020 & $5 / 5 / 2020$ & $5 / 8 / 2020$ & 92 \\
\hline Impuesto sobre Casinos de Juego 052020 & $5 / 6 / 2020$ & $7 / 9 / 2020$ & 94 \\
\hline
\end{tabular}

Fuente. elaborado con datos de los avisos publicados en la web www.dgii.gov.do .

1 La Dirección General de Impuestos Internos es la Administración Tributaria u organismo encargado de administrar y recaudar los principales impuestos internos y tasas en la República Dominicana. 


\section{Prórrogas en pagos de impuestos}

\begin{tabular}{|l|r|r|r|}
\hline \multicolumn{1}{|c|}{ Obligaciones Fiscales } & & & \\
\hline \multicolumn{1}{|c|}{} & & & \\
\hline 1era. Cuota Anticipo ISR PF y Sucesiones Indivisas & $30 / 6 / 2020$ & $31 / 8 / 2020$ & Prórroga en días \\
\hline 2da. Cuota Anticipo ISR PF y Sucesiones Indivisas & $30 / 9 / 2020$ & $30 / 10 / 2020$ & 30 \\
\hline 1ra. cuota ISA de ISR PF Negocios unico dueño & $29 / 5 / 2020$ & $29 / 7 / 2020$ & 61 \\
\hline 1ra. cuota ISA de PJ con cierre 122019 & $29 / 5 / 2020$ & $29 / 7 / 2020$ & 61 \\
\hline 1ra. cuota ISA de PJ con cierre 032020 & $29 / 7 / 2020$ & $31 / 8 / 2020$ & 33 \\
\hline 2da. cuota ISA PJ con cierre 062019 & $30 / 4 / 2020$ & $29 / 5 / 2020$ & 29 \\
\hline 1era Cuota RST Ingresos PF y del sector agropecuario & $20 / 3 / 2020$ & $29 / 7 / 2020$ & 131 \\
\hline 1ra. cuota del RST Ingresos PJ y por compras & $31 / 3 / 2020$ & $29 / 7 / 2020$ & 120 \\
\hline 2da. cuota del RST Ingresos PJ y por compras & $30 / 6 / 2020$ & $31 / 12 / 2020$ & 184 \\
\hline
\end{tabular}

Fuente. Elaborado con datos de los avisos publicados en la web www.dgii.gov.do

\section{B. Exoneraciones de Impuestos}

\begin{tabular}{|c|c|}
\hline \multicolumn{2}{|r|}{ Exoneraciones Temporales } \\
\hline $\begin{array}{c}\text { Impuesto Sobre la } \\
\text { Renta - ISR }\end{array}$ & $\begin{array}{l}\text { - Pago de anticipos correspondientes a las declaraciones de } \\
\text { Impuesto Sobre la Renta de las Personas Jurídicas y Negocios } \\
\text { de Unico Dueño, para los periodos abril, mayo, junio y julio. } \\
\text { - Esta disposición no aplica para los grandes contribuyentes, } \\
\text { excepto aquellos con impedimento para operar durante el } \\
\text { estado de emergencia declarado con el Decreto núm. 134-20 } \\
\text { de fecha } 19 \text { de marzo de } 2020 \text {. } \\
\text { - Pago del primer anticipo de ISR correspondientes a personas } \\
\text { fisicas y sucesiones indivisas del periodo fiscal 2019, con } \\
\text { ingresos presentados no mayores a RD } \$ 8,700,000.00 \text {. }\end{array}$ \\
\hline $\begin{array}{l}\text { Impuesto a los } \\
\text { Activos - ISA }\end{array}$ & $\begin{array}{l}\text { Los contribuyentes clasificados como micro y pequeñas empresas } \\
\text { conforme con la Ley núm. 187-17, sobre el Régimen Regulatorio } \\
\text { de las Micro, Pequeñas y Medianas Empresas, quedaron exonerados } \\
\text { del pago de la 1ra cuota del Impuesto a los Activos (ISA) cuyo venci- } \\
\text { miento fue el } 29 \text { de junio de 2020, así como aquellos contribuyentes } \\
\text { con cierre fiscal } 30 \text { de junio de 2020, bajo las mismas condiciones, } \\
\text { y que les correspondía el pago de la 2da cuota del ISA, cuyo venci- } \\
\text { miento fue el } 29 \text { de mayo de } 2020 \text {. }\end{array}$ \\
\hline
\end{tabular}

Fuente. Elaborado con datos de los avisos publicados en la web www.dgii.gov.do 


\section{Diferimiento de cuotas y acuerdos de pago}

\begin{tabular}{|c|c|}
\hline \multicolumn{2}{|r|}{ Acuerdos de pagos y Prórrogas de Pagos } \\
\hline ITBIS/IVA $^{2}$ & $\begin{array}{l}\text { - Los contribuyentes tuvieron la facilidad de solicitar acuerdos de } \\
\text { pago de hasta cuatro cuotas para el Impuesto sobre Transferencias } \\
\text { de Bienes Industrializados y Servicios (ITBIS), correspondiente al } \\
\text { periodo fiscal febrero de 2020, cuya fecha límite de declaración y } \\
\text { pago era el } 20 \text { de marzo de } 2020 \text {. } \\
\text { - } \quad \text { Igualmente, hubo un aplazamiento hasta el } 24 \text { de abril para el } \\
\text { pago de la segunda cuota de febrero y la primera cuota de marzo } \\
2020 \text { del referido impuesto. } \\
\text { - Se ofreció la opción de un acuerdo de pago de tres cuotas } \\
\text { mensuales iguales y consecutivas a todos los contribuyentes del } \\
\text { Impuesto sobre ITBIS para el periodo marzo } 2020 \text {. }\end{array}$ \\
\hline $\begin{array}{l}\text { Impuesto Sobre la } \\
\text { Renta - ISR Personas } \\
\text { físicas y Sucesiones } \\
\text { Indivisas }\end{array}$ & $\begin{array}{l}\text { Los contribuyentes podrán liquidar el Impuesto Sobre la Renta } \\
\text { mediante el pago de cuatro cuotas iguales y consecutivas, las cuales } \\
\text { no estarán sujetas al interés indemnizatorio mensual y serán generadas } \\
\text { automáticamente al momento del pago de la declaración jurada. }\end{array}$ \\
\hline $\begin{array}{l}\text { Impuesto Selectivo al } \\
\text { Consumo - ISC }\end{array}$ & $\begin{array}{l}\text { Para las obligaciones referentes al Impuesto Selectivo al Consumo (ISC) } \\
\text { de productos del Alcohol y del Tabaco del periodo marzo 2020, les ha } \\
\text { sido otorgado un acuerdo de pago de tres cuotas mensuales iguales y } \\
\text { consecutivas sin incluir interés indemnizatorio. }\end{array}$ \\
\hline $\begin{array}{l}\text { Impuesto a los } \\
\text { activos - ISA }\end{array}$ & $\begin{array}{l}\text { Los contribuyentes del Impuesto sobre Activos con fecha de cierre } \\
31 \text { de diciembre, que no fueron beneficiados por la exención de } \\
\text { este impuesto, podrán efectuar el pago de la 1ra cuota del impuesto } \\
\text { mediante un acuerdo de tres cuotas iguales y consecutivas, a ser pagadas } \\
\text { en el trimestre junio-agosto del presente año. Las cuotas del acuerdo } \\
\text { no estarán sujetas al interés indemnizatorio y serán generadas automá- } \\
\text { ticamente al momento de presentar la Declaración Jurada del citado } \\
\text { impuesto. }\end{array}$ \\
\hline $\begin{array}{l}\text { Reducción al } 50 \% \\
\text { valor cuotas }\end{array}$ & $\begin{array}{l}\text { Otra medida relacionada corresponde a la reducción a la mitad del } \\
\text { valor actual de las cuotas de todos los acuerdos de pago vigentes a partir } \\
\text { del } 19 \text { de marzo de } 2020 \text {, duplicando el plazo de vigencia de las cuotas } \\
\text { pendientes de pago. Mediante los avisos informativos } 36-20 \text { y } 76-20 \\
\text { la DGII aplazó por varios meses las cuotas de los acuerdos de pagos } \\
\text { vigentes a la fecha y tenían compromisos de pagos con el fisco para los } \\
\text { periodos que para los periodos abril, mayo y junio. }\end{array}$ \\
\hline
\end{tabular}

Fuente. Elaborado con datos de los avisos publicados en la web www.dgii.gov.do

2 Impuesto sobre la Transferencias de Bienes Industrializados (ITBIS) y Servicios, conocido en otros países como Impuesto al Valor Agregado (IVA). 


\section{Control y Fiscalización}

Las funciones de control y fiscalización en la Administración Tributaria son procesos que se han visto afectados por la crisis, considerando el tema del contacto directo con el contribuyente que estas conllevan. Debido a ello vale resaltar las medidas que a este respecto se han tomado en el país:

\section{A. Fiscalizaciones}

Respecto a la función de fiscalización, tanto las notificaciones como las auditorías en proceso, se han visto mermadas significativamente, inclusive muchas auditorías han sido paralizadas, ya que las condiciones económicas y sanitarias actuales no permiten la continuidad de las mismas, y aquellas que han continuado han sido bajo un marco operativo pasivo ante las circunstancias expuestas. Consideramos que probablemente en un futuro próximo únicamente los contribuyentes que no tuvieron tanto impacto negativo en esta crisis sean los principales candidatos a las fiscalizaciones, así como también aquellos que hayan aprovechado el momento de crisis para ejercer actividades económicas sin pagar los impuestos correspondientes al fisco.

Adicionalmente, se prevé que las medidas que las autoridades fiscales en torno a las fiscalizaciones se comiencen a materializar a partir de mediados del ańo 2021, ya que en esta línea de tiempo la autoridad tributaria tendría las informaciones necesarias para hacer las verificaciones de lugar. 
- Suspensión de notificaciones de control

$\mathrm{Al}$ igual que las notificaciones de fiscalización, las correspondientes a los casos de control han sufrido el mismo efecto de suspensión. Estas comunicaciones normalmente le informan al contribuyente la omisión de algún cumplimiento fiscal o la morosidad que pudiese presentar en las declaraciones de impuestos que ha declarado.

\section{B. Control de Contribuyentes}

La parte operativa relacionada con el Control de los Contribuyentes se realiza en las Administraciones Locales, las cuales funcionan como puntos operativos a gran escala. En este sentido, siendo que las funciones directas de control recaen sobre estas dependencias, las mismas han continuado dando el servicio tanto de forma exclusiva mediante citas, como de manera remota ${ }^{3}$, lo que ha permitido que el contribuyente mantenga el contacto sin tener que apersonarse a la institución.

A continuación, se muestran los principales servicios ofrecidos en las modalidades antes expuestas:

3 La DGII ha publicado en su página web, los correos electrónicos de las Administraciones Locales para asistencia remota: https://dgii.gov.do/publicacionesOficiales/avisosInformativos/Documents/2020/64-20.pdf 


\begin{tabular}{|c|c|}
\hline \multicolumn{2}{|r|}{ Control de Contribuyentes } \\
\hline \multirow{15}{*}{$\begin{array}{c}\text { Solicitudes por Correo } \\
\text { Electrónico }\end{array}$} & Solicitudes por Correo Electrónico \\
\hline & Rectificativas de Declaraciones Juradas \\
\hline & Certificaciones sin firma Digital \\
\hline & Incorporaciones al Registro Nacional de Contribuyentes (RNC) \\
\hline & Modificaciones al Registro Nacional de Contribuyentes (RNC) \\
\hline & Acuerdos de Pago \\
\hline & Pagos a Cuenta \\
\hline & Transferencias Inmobiliarias \\
\hline & Pagos de Hipotecas de Inmuebles \\
\hline & Solicitud de Exención de Anticipos \\
\hline & Solicitud de Pago de Deudas \\
\hline & Sucesiones y Donaciones \\
\hline & Cese Temporal de Operaciones \\
\hline & Compensación Automática de Activos \\
\hline & Certificaciones de Personas Físicas sin acceso a la Oficina Virtual. \\
\hline \multirow{3}{*}{$\begin{array}{l}\text { Servicios Presenciales } \\
\quad \text { (cita previa ) }\end{array}$} & Venta de sellos para el Colegio de Abogados \\
\hline & Recibos de la Ley núm. 33-91 (Ley núm. 3-19) \\
\hline & Atención de casos especiales a solicitud del contribuyente. \\
\hline
\end{tabular}

Fuente. Elaborado con datos de los avisos publicados en la web www.dgii.gov.do

\section{Apoyo electrónico para trámites}

Desde mucho antes de la pandemia existían una serie de solicitudes que el contribuyente podía gestionar a través de su Oficina Virtual en la página de la DGII ${ }^{4}$. La DGII contaba con la preparación tecnológica para asumir esta crisis, por lo que durante este período solo se han desplegado las siguientes facilidades complementarias:

4 Portal DGII: www.dgii.gov.do 


\begin{tabular}{|c|c|}
\hline \multicolumn{2}{|c|}{ Nuevos trámites electrónicos habilitados } \\
\hline Rectificativas en línea & $\begin{array}{l}\text { Desde el pasado } 26 \text { de mayo es posible la realización } \\
\text { de las modificaciones de declaraciones juradas a } \\
\text { través de la Oficina Virtual, siempre que estas se } \\
\text { encuentren dentro de la fecha hábil. Esta facilidad } \\
\text { está disponible para el Impuesto Sobre la Renta } \\
\text { Sociedades (IR2), Impuesto sobre la Renta Personas } \\
\text { Físicas (IR1) e Impuesto Sobre Activos (ACT), a } \\
\text { partir del cierre fiscal } 31 \text { de diciembre de } 2019 \text { y del } \\
\text { periodo fiscal mayo } 2020 \text { para ITBIS. }\end{array}$ \\
\hline $\begin{array}{c}\text { Certificaciones Digitales } \\
\text { de Inmuebles }\end{array}$ & $\begin{array}{l}\text { Las Personas Jurídicas propietarias de inmuebles, que } \\
\text { estén al día en el cumplimiento de sus obligaciones } \\
\text { del Impuesto Sobre la Renta (ISR) e Impuesto Sobre } \\
\text { Activos (ISA), pueden generar las certificaciones de } \\
\text { los inmuebles digitalmente. }\end{array}$ \\
\hline $\begin{array}{l}\text { Actualización de datos } \\
\text { del Registro Nacional del } \\
\text { Contribuyente (RNC) }\end{array}$ & $\begin{array}{l}\text { Tanto Personas Físicas como Jurídicas pueden } \\
\text { solicitar actualizaciones a los datos del registro } \\
\text { básico, como remitir nuevas solicitudes de cambio } \\
\text { de accionistas, aumento/disminución de capital, } \\
\text { adición de sucursales, entre otras. }\end{array}$ \\
\hline $\begin{array}{c}\text { Modificación de } \\
\text { Declaraciones Juradas }\end{array}$ & $\begin{array}{l}\text { Para las declaraciones juradas del Impuesto Sobre la } \\
\text { Renta de Sociedades (IR2), Impuesto sobre la Renta } \\
\text { Personas Físicas (IR1) e Impuesto Sobre Activos } \\
\text { (ACT) a partir del cierre fiscal } 31 \text { de diciembre } \\
\text { 2019, y para el caso del ITBIS, a partir del periodo } \\
\text { fiscal mayo 2020, es posible la modificación de la } \\
\text { declaración en los casos que se requiera eliminar esta, } \\
\text { presentada nuevamente por la vía web. Excepto las } \\
\text { declaraciones juradas que han sido objeto de pagos } \\
\text { parciales, fruto de un acuerdo de pago. }\end{array}$ \\
\hline
\end{tabular}

Fuente. Elaborado con datos de los avisos publicados en la web www.dgii.gov.do

\section{Medidas tributarias implementadas por la Dirección General de Aduanas (DGA)}

El segundo organismo recaudador del país, según el peso de los ingresos tributarios es la Dirección General de Aduanas (DGA), este organismo también está ejecutando medidas de apoyo a los contribuyentes y a la ciudadanía. 


\begin{tabular}{|l|l|}
\hline \multicolumn{2}{|c|}{ Suspensión temporal de la aplicación del ITBIS/IVA } \\
\hline $\begin{array}{l}\text { Importación de las empresas } \\
\text { amparadas en la Ley núm. 392-07, } \\
\text { sobre Competitividad e Innovación } \\
\text { Industrial (PROINDUSTRIA) y sus } \\
\text { modificaciones }\end{array}$ & $\begin{array}{l}\text { A los bienes que estén gravados con } \\
\text { un } 0 \% \text { de arancel, con arreglo a lo } \\
\text { dispuesto en el artículo 20 de dicha ley, } \\
\text { no a otros bienes industriales, ni a bienes } \\
\text { gravados con arancel o que, a causa de } \\
\text { la aplicación de un acuerdo de libre } \\
\text { comercio, disfruten de una preferencia } \\
\text { arancelaria del 0 \%. }\end{array}$ \\
\hline $\begin{array}{l}\text { Importación de las empresas que } \\
\text { operan bajo la Ley núm. 56-07, que } \\
\text { declara de prioridad nacional los } \\
\text { sectores pertenecientes a la cadena } \\
\text { textil, confección y accesorio; } \\
\text { pieles, fabricación de calzados de } \\
\text { manufactura de cuero y crea un } \\
\text { régimen nacional regulatorio para } \\
\text { estas industrias }\end{array}$ & $\begin{array}{l}\text { A las importaciones de los sectores } \\
\text { pertenecientes a la cadena textil, } \\
\text { confección y accesorios, pieles, } \\
\text { fabricación de calzados de manufactura } \\
\text { de cuero. }\end{array}$ \\
\hline $\begin{array}{l}\text { Importaciones de productos, insumos } \\
\text { y equipos médicos y la transferencia en } \\
\text { el mercado local }\end{array}$ & $\begin{array}{l}\text { caucho para cirugía, mascarillas, } \\
\text { aparatos respiratorios de reanimación, } \\
\text { termómetros de uso clínico, prendas y } \\
\text { complementos de vestir de uso médico, } \\
\text { entre otros. }\end{array}$ \\
\hline
\end{tabular}

Fuente. Elaborado con datos de los avisos publicados en la web www.dgii.gov.do

\section{Medidas sociales}

La República Dominicana está ejecutando diversos programas de ayudas sociales, entre estos hay tres que tienen un impacto transversal en la económica doméstica y empresarial, ayudando así a mitigar la desigualdad social que crean los efectos de la pandemia en la economía local (Ministerio de Hacienda, 2020).

Estas medidas sociales son, a saber, los programas "Quédate en Casa”, "Fondo de Asistencia Solidaria a Empleados (FASE)" y el "Programa de Asistencia al Trabajador Independiente ( $\mathrm{Pa}$ ' $\mathrm{Ti}$ ), que hasta el momento se mantendrán vigentes hasta el 15 de agosto de 2020 (Presidente de la República, 2020). 


\begin{tabular}{|c|c|c|c|}
\hline Medidas sociales & $\begin{array}{l}\text { Programa "Quédate en } \\
\text { Casa" }\end{array}$ & $\begin{array}{l}\text { Programa Fondo de } \\
\text { Asistencia Solidaria a } \\
\text { Empleados (FASE) }\end{array}$ & $\begin{array}{l}\text { Programa de } \\
\text { Asistencia al } \\
\text { Trabajador } \\
\text { Independiente } \\
\text { (Pa' Ti) }\end{array}$ \\
\hline Objetivo & $\begin{array}{l}\text { Asegurar la alimentación } \\
\text { de familias integradas } \\
\text { por trabajadores } \\
\text { informales de menores } \\
\text { ingresos y en condiciones } \\
\text { de vulnerabilidad, } \\
\text { identificados por el } \\
\text { Gabinete Social. }\end{array}$ & $\begin{array}{l}\text { Apoyar de manera } \\
\text { transitoria a los } \\
\text { trabajadores formales } \\
\text { suspendidos (FASE 1) o } \\
\text { con contratos de trabajos } \\
\text { activos (FASE 2) del sector } \\
\text { privado } \text {, sobre la base de } \\
\text { los reportes de la Tesorería } \\
\text { de la Seguridad Social } \\
\text { (TSS) para el mes de } \\
\text { febrero de 2020, y no ser } \\
\text { beneficiarios de Quédate } \\
\text { en Casa. }\end{array}$ & $\begin{array}{l}\text { Apoyar a los } \\
\text { trabajadores } \\
\text { independientes } \\
\text { que tengan un } \\
\text { préstamo registrado } \\
\text { en una entidad de } \\
\text { intermediación } \\
\text { financiera o un } \\
\text { programa de } \\
\text { financiamiento } \\
\text { administrado por el } \\
\text { Gobierno, a través } \\
\text { de una transferencia } \\
\text { monetaria no } \\
\text { condicionada. }\end{array}$ \\
\hline $\begin{array}{l}\text { Cantidad de } \\
\text { beneficiarios }\end{array}$ & $\begin{array}{l}1.6 \text { millones de hogares, } \\
\text { el cual incluye a } 811,003 \\
\text { familias que en la } \\
\text { actualidad se benefician } \\
\text { de "Comer es Primero"6 y } \\
780,000 \text { nuevos hogares". }\end{array}$ & $\begin{array}{l}905,857 \text { empleados } \\
\text { del sector privado, que } \\
\text { laboran para } 51,572 \\
\text { empresas }^{8} \text {. }\end{array}$ & $\begin{array}{l}189,767^{9} \text { trabajadores } \\
\text { formalizados, pero } \\
\text { que ejercen sus } \\
\text { actividades de manera } \\
\text { independiente. }\end{array}$ \\
\hline
\end{tabular}

5 En la actualidad, una empresa puede tener trabajadores en FASE I y FASE II simultáneamente.

6 Es un programa social de hogares que tienen índice de Calidad de Vida (ICV) I y II, es decir, hogares en pobreza extrema y en pobreza moderada. Su objetivo es complementar la alimentación básica de los hogares en situación de pobreza. http://www. adess.gob.do/subsidios/programa-comer-es-primero/

7 Cantidad de beneficiarios indicados en el informe final de rendición del estado de emergencia del Decreto núm. 134-20, emitido por el Presidente de la República, en fecha 10 de julio de 2020, presentado al Congreso Nacional.

8 Cantidad de beneficiarios indicados en https://www.hacienda.gob.do/ministerio-de-hacienda-garantiza-a-partir-de-hoy-pagos-de-primera-quincena-de-fase/.

9 Cantidad de beneficiarios indicados en el informe final de rendición del estado de emergencia del Decreto núm. 134-20, emitido por el Presidente de la República, en fecha 10 de julio de 2020, presentado al Congreso Nacional. 


\begin{tabular}{|c|c|c|c|}
\hline $\begin{array}{l}\text { Monto de la } \\
\text { ayuda }\end{array}$ & $\begin{array}{l}\text { RD } \$ 5,000.00 \text { mensuales } \\
\text { y en aquellos hogares } \\
\text { con algún miembro } \\
\text { mayor a } 60 \text { años o con } \\
\text { precondición de salud } \\
\text { la transferencia puede } \\
\text { llegar a RD } \$ 7,000.00 \\
\text { mensuales. }\end{array}$ & $\begin{array}{l}\text { FASE 1: Nunca será } \\
\text { menos de RD } \$ 5,000.00 \\
\text { ni mayor de RD } \$ 8,500.00 \\
\text { mensuales. } \\
\text { FASE 2: RD } \$ 5,000.00 \\
\text { mensuales. }\end{array}$ & $\begin{array}{l}\mathrm{RD} \$ 5,000.00 \\
\text { mensuales. }\end{array}$ \\
\hline $\begin{array}{l}\text { Modalidad de } \\
\text { entrega }\end{array}$ & $\begin{array}{l}\text { A través de la tarjeta } \\
\text { de solidaridad a los } \\
\text { beneficiarios de "Comer } \\
\text { es primero" o con el } \\
\text { número de cédula de } \\
\text { identidad para los nuevos } \\
\text { beneficiarios }{ }^{10} \text {. }\end{array}$ & $\begin{array}{l}\text { Transferencia a su cuenta } \\
\text { de nómina, en caso de no } \\
\text { tenerla se apertura una } \\
\text { cuenta de nómina en el } \\
\text { Banco de Reservas de la } \\
\text { República Dominicana a } \\
\text { su nombre. }\end{array}$ & $\begin{array}{l}\text { Transferencia a la } \\
\text { cuenta bancaria del } \\
\text { trabajador, en caso } \\
\text { de no tenerla se } \\
\text { apertura una cuenta en } \\
\text { el Banco de Reservas } \\
\text { de la República } \\
\text { Dominicana a su } \\
\text { nombre. }\end{array}$ \\
\hline Vigencia & $\begin{array}{l}\text { Desde el mes de abril } \\
\text { hasta el } 15 \text { de agosto de } \\
2020 .\end{array}$ & $\begin{array}{l}\text { Desde el mes de abril } \\
\text { hasta el } 15 \text { de agosto de } \\
2020\end{array}$ & $\begin{array}{l}\text { Desde el mes de mayo } \\
\text { hasta el } 15 \text { de agosto de } \\
2020 \text { (el pago inicia en } \\
\text { junio). }\end{array}$ \\
\hline $\begin{array}{l}\text { Fuente de } \\
\text { financiamiento }\end{array}$ & \multicolumn{3}{|c|}{$\begin{array}{l}\text { Al mes de mayo el Gobierno utilizó en la implementación y puesta en marcha } \\
\text { del programa "Quédate en Casa" y el Fondo de Asistencia al Empleado (FASE), } \\
\text { RD } \$ 12,000 \text { millones del Instituto Dominicano de Prevención y Protección de } \\
\text { Riesgos Laborales (IDOPRIL), un financiamiento de RD\$12,000 millones del } \\
\text { Banco Central de la República Dominicana y US\$150 millones que estaban } \\
\text { aprobados como facilidad en caso de catástrofe por el Banco Mundial }{ }^{11} \text {. }\end{array}$} \\
\hline $\begin{array}{l}\text { Estimación } \\
\text { financiera }\end{array}$ & \multicolumn{3}{|c|}{$\begin{array}{l}\text { Con la implementación del Programa de Asistencia al Trabajador Independiente } \\
\text { (Pa' Ti), al mes de junio, el costo de atención a la pandemia alcanzará unos } \\
\text { RD } \$ 57,599 \text { millones }^{12} \text {. }\end{array}$} \\
\hline
\end{tabular}

Fuente. Elaborado con los datos publicados en la sesión de prensa de la web www.hacienda.gov.do

10 El formato de la ayuda monetaria funciona como un monedero electrónico, donde el beneficiario acude a los comercios de alimentos afiliados a la Red de Abastecimiento Social (RAS) para adquirir los alimentos y utensilios de limpieza en sus establecimientos. 11 Información consultada en https://www.hacienda.gob.do/gobierno-sometera-este-mes-un-presupuesto-complementario-al-congreso-nacional/.

12 Información disponible en https://www.hacienda.gob.do/mas-de-200-mil-trabajadores-seran-beneficiados-con-el-programa-de-asistencia-al-trabajador-independiente-pa-ti/. 


\section{Temas de intéres tributario local en medio de la pandemia}

La economía digital por su impacto durante la crisis actual no pueden ser dejado de lado, debido a que, ha cobrado notoriedad e importancia ante el distanciamiento social y a lo que se ha llamado "El gran confinamiento" que ha forzado el auge del comercio electrónico. De igual manera, resulta interesante analizar los resultados que se han podido observar en la República Dominicana con la implementación de la factura electrónica luego de iniciada la crisis, así como medidas sobre los precios de transferencia.

\section{Efectos de la COVID-19 en la economía digital a nivel local}

La COVID-19 ha planteado un desafío global, impactando de forma directa o indirecta todos los aspectos de una sociedad. Ha puesto a prueba todas las formas de organización y comercio de la economía, y la República Dominicana no es la excepción a esta nueva regla. Empero, conforme vamos avanzando, el impacto de la pandemia establecerá consecuencias sociales y sobre todo económicas. Significará cambios en cotidianidad y en el intercambio de bienes y servicios.

Meses antes de desatarse esta pandemia, las empresas pequeñas, medianas y hasta grandes enfrentaban grandes desafíos respecto de su operatividad y forma de negocio y es que, dentro de un contexto globalizado e hiper-conectado, era necesario hablar de una digitalización de la economía, un cambio en la forma de operar para llegar a más usuarios o impactar de manera positiva la marca. Ahora, el tema cobra mayor relevancia, pues pone en ejecución planes, diseños y planteamientos sobre su funcionalidad e imposición que se encontraba, en muchas ocasiones, en el papel.

La digitalización, que antes parecía un "extra" para aumentar la productividad y las ganancias, hoy se ha vuelto un requisito para que las empresas sobrevivan. La República Dominicana está, actualmente, inmersa en implementar nuevas estrategias para la reducción de la brecha digital. Por lo tanto, las nuevas tecnologías y la sinergia entre esta y la información, traen consigo un cambio estructural tanto a nivel social como normativo. 
Estos cambios exigirán una serie de habilidades y políticas de protección social de nueva generación, y en nuestro país supondrá un repensar de los aspectos normativos aplicables a la situación, incluyendo regular aspectos de tributación. No obstante, la tributación de la economía digital es asunto complejo porque afecta derechos humanos, el comercio, la creación y captura de valor económico, la aplicación de la ley y la seguridad nacional, sin mencionar el aspecto tributario que aplicaría a una actividad dentro de esta rama y la debida distribución de los beneficios.

\section{La facturación electrónica}

En la República Dominicana recibe el nombre de Comprobante Fiscal Electrónico (e-CF) y es regulado por la Dirección General de Impuestos Internos (DGII). El Comprobante Fiscal Electrónico (e-CF), es el documento electrónico firmado digitalmente que acredita la transferencia de bienes, entrega en uso o la prestación de servicios, y al igual que un comprobante normal, debe cumplir siempre con los requisitos establecidos en la normativa dispuesta para estos fines en el país, esto de acuerdo al Decreto núm. 254-06 (DGII, Norma General 01-2020, 2020)

La implementación de la facturación electrónica es reciente, apenas en enero pasado, con la Norma General núm. 01-2020 que regula la emisión y el uso de los Comprobantes Fiscales Electrónicos (e-CF). El modelo de operación comprende importantes ventajas para los contribuyentes, y sobre todo supone una superioridad que en este momento crucial, es una ventaja competitiva.

Precisamente en los meses de la cuarentena ha crecido la emisión de Comprobantes Fiscales Electrónicos, hecho que respalda el planteamiento sobre los beneficios de este método para los contribuyentes, por lo que el impacto en este aspecto podríamos decir que ha sido positivo.

\section{Precios de transferencia en tiempo de crisis}

Los modelos de operaciones de negocios están siendo replanteados, y asimismo la forma de regularlos. A nivel administrativo, la pandemia ha hecho que las empresas hagan un esfuerzo adicional sobre sus operaciones. Ha supuesto una baja en las actividades de ventas de bienes 
y servicios, cierre de establecimientos y la paralización de actividades productivas, por lo que resultaría necesario una revisión integral y recopilación de información importante sobre el grupo al que pertenecen.

Entendemos que probablemente, conllevará una modificación de las políticas internas sobre Precios de Transferencia que se mantenían antes de la pandemia, para ahora adaptarla a la situación actual, según de hecho ya lo ha sugerido la OCDE ${ }^{13}$. La información es clave en materia de precios de transferencia y lo será aún más luego de esta crisis.

A continuación nos referiremos brevemente a las medidas tomadas por la Administración Tributaria dominicana en materia de Precios de Transferencia:

\begin{tabular}{|c|l|}
\hline $\begin{array}{c}\text { Suspensión de } \\
\text { las tasas }\end{array}$ & $\begin{array}{l}\text { Se suspendieron las tasas determinadas a través del Acuerdo de } \\
\text { Precios Anticipados para el Sector Hotelero, conforme decisión } \\
\text { tomada por el Gobierno el 17 de marzo de 2020. Para el cierre } \\
\text { de este ańo 2020 se prevé que los ingresos por turismo se redu- } \\
\text { zcan alrededor de 30\%, lo que equivale a un 2.3\% del Producto } \\
\text { Interno Bruto (PIB). }\end{array}$ \\
\hline $\begin{array}{c}\text { Concesión de } \\
\text { prórrogas }\end{array}$ & $\begin{array}{l}\text { Se prorrogó la presentación de la Declaración Informativa de } \\
\text { Operaciones efectuadas con Partes Relacionadas (DIOR), con } \\
\text { fecha de cierre 30 de septiembre. De igual manera fue prorrogada } \\
\text { la DIOR correspondiente a la fecha de cierre 31 de diciembre, para } \\
\text { este caso se aplazó la fecha límite desde el 30 de junio de 2020 hasta } \\
\text { el 29 de julio de 2020. }\end{array}$ \\
\hline
\end{tabular}

Los precios de transferencia tendrán desafíos importantes para los cuales es muy probable que los organismos internacionales que regulan su práctica (tal es el caso de la OCDE) emitan normativas para velar por el correcto cumplimiento del conocido principio de valor de mercado.

13 La OCDE es Organización para la Cooperación y el Desarrollo Económicos. Esta organización establece estándares internacionales y propone soluciones basadas en datos empíricos a diversos retos sociales, económicos y medioambientales, siendo un foro único y un centro de conocimientos para la recopilación de datos y el análisis, el intercambio de experiencias y de buenas prácticas, para asesorar en materia de políticas públicas y en el establecimiento de estándares y normas a nivel mundial. 


\section{Conclusiones y recomendaciones}

Recientemente la DGII ha publicado sus Memorias Institucionales 2016-2020, en las cuales abordan las medidas de facilitación tributaria que han beneficiado a más de 181,000 contribuyentes (DGII, 2020), de lo anterior podemos identificar que han cumplido su cometido, pero son suficientes estas medidas ante el escenario actual dominicano?

Sin duda, la pandemia llegó en un momento crucial para el país en el contexto político y fiscal, y el apoyo de Administración Tributaria dominicana ha sido vital en el respaldo de los contribuyentes y ciudadanos, ya que estas medidas de facilitación también buscan sostener la recaudación para garantizar que el país siga trabajando en bien de los más desfavorecidos.

A pesar del alivio que han significado estas medidas para los contribuyentes, es nuestro parecer que el sistema fiscal dominicano debe continuar fortaleciéndose para poder apoyar al Estado ante la inminente crisis económica que se avecina por medio de la evaluación de acciones de apoyo al contribuyente, simplificación y reformas, para seguir impulsando el cumplimiento tributario. En ese mismo sentido, nos resulta innegable que como país tenemos grandes retos por delante ante un mundo que ya ha cambiado y se ha visto forzado a asumir la Economía Digital, el reto principal en términos tributarios es la Digitalización de la Administración Tributaria. Las estructuras de negocios presentan como retos la atribución de beneficios, el Domicilio Permanente Digital y la Atribución de riesgos, y estos desafíos deben ser abordados desde la implementación de políticas públicas, debe estructurarse un sistema de regulación capaz de hacer eficiente la relación de la economía digital con los demás aspectos cotidianos para lograr la imposición justa de las plataformas digitales.

Se dice que "las grandes crisis son también grandes oportunidades" y es por esto que vemos la crisis de la COVID-19 como un momento oro para replantearnos como país, de forma tal que las facilidades fiscales y programas sociales también traigan como resultado un impacto positivo en la economía dominicana, ¡que tanto lo necesita! Por tanto, se hace necesario continuar implementando políticas que fortalezcan el aparato productivo y la economía, y que sobretodo, puedan magnificar lo ya logrado hasta ahora, impactando desde la perspectiva tributaria y social, con las decisiones que estamos abocados a tomar para la post-pandemia. 


\section{Referencias}

Código Tributario Dominicano [CTD]. Ley 11-92. (s.f.). (República Dominicana).

Conferencia de las Naciones Unidas sobre Comercio y Desarrollo (UNCTAD). (2019). Informe sobre economía digital. Ginebra.

Decreto Número 137-20. [Presidencia de la República]. (2020). Santo Domingo.

Decreto Número 143-20. [Presidente de la República]. (2 de abril de 2020). Santo Domingo, Distrito Nacional, República Dominicana. Decreto Número 184-20. [Presidente de la República]. (29 de mayo de 2020). Santo Domingo, Distrito Nacional, República Dominicana. Decreto Núm. 185-20. [Presidente de la República]. (29 de mayo de 2020). Santo Domingo, Distrito Nacional, República Dominicana. Decreto Número 242-20. [Presidente de la República]. (8 de julio de 2020). Santo Domingo, Distrito Nacional, República Dominicana.

Dirección General de Impuestos Internos [DGII]. Norma General 012020. (2020). Norma General que Regula la Emisión y el Uso de los Comprobantes.

Dirección General de Impuestos Internos [DGII]. (17 de mayo de 2020). DGII avanza en reforma e-CF; recibe 10 millones de comprobantes electrónicos. Recuperado de www.dgii.gov.do: https://dgii.gov.do/ noticias/Paginas/DGII-avanza-en-reforma-e-CF-recibe-10-millones-de-comprobantes-electronicos.aspx

Dirección General de Impuestos Internos [DGII]. (2020). Informe de recaudación enero-abril 2020.

Dirección General de Impuestos Internos. (2020). Memorias Institucionales 2016-2020.

Fondo Monetario Internacional. (Enero 2019). Tributación Internacional de las Empresas. Documento de Política del FMI.

Henriquez, P. (Consulta en línea el 5 de mayo de 2020). COVID-19: ¿ ¿na oportunidad para la transformación digital de las pymes? [Entrada de un blog]. Puntos sobre la i. Recuperado de https://blogs.iadb.org/ innovacion/es/covid-19-oportunidad-transformacion-digital-pymes.

Ministerio de Hacienda. (30 de marzo de 2020). Gobierno Dominicano utilizará financiamiento contratado con el Banco Mundial 
para atender emergencia por coronavirus. Recuperado de https:// www.hacienda.gob.do/gobierno-dominicano-utilizara-financiamiento-contratado-con-el-banco-mundial-para-atender-emergencia-por-coronavirus/

Ministerio de Hacienda. (27 de marzo de 2020). Gobierno lanza un paquete de ayuda económica para proteger a la República Dominicana. Recuperado de https://www.hacienda.gob.do/gobierno-lanza-un-paquete-historico-de-ayuda-economica-para-proteger-a-la-republica-dominicana/

Ministerio de Hacienda. (2 de abril de 2020). Gobierno iniciará pagos a beneficiarios del programa Quédate en Casa a partir de mañana. Recuperado de https://www.hacienda.gob.do/gobierno-iniciara-pagos-a-beneficiarios-del-programa-quedate-en-casa-a-partir-de-manana/

Ministerio de Hacienda. (7 de abril de 2020). Ministerio de Hacienda acredita las cuentas de 295 mil trabajadores formales a través de fase. Recuperado de https://www.hacienda.gob.do/ministerio-de-hacienda-acredita-las-cuentas-de-295-mil-trabajadores-formales-a-traves-de-fase/

Ministerio de Hacienda. (5 de mayo de 2020). Gobierno someterá este mes un presupuesto complementario al Congreso Nacional. Recuperado de https://www.hacienda.gob.do/gobierno-sometera-este-mes-un-presupuesto-complementario-al-congreso-nacional/

Ministerio de Hacienda. (20 de mayo de 2020). Más de 200 mil trabajadores serán beneficiados con el programa de Asistencia al Trabajador Independiente (pa' ti). Recuperado de https://www. hacienda.gob.do/mas-de-200-mil-trabajadores-seran-beneficiados-con-el-programa-de-asistencia-al-trabajador-independiente-pa-ti/

Ministerio de Hacienda. (13 de julio de 2020). Ministerio de Hacienda garantiza a partir de hoy pagos de primera quincena de fase. Recuperado de https://www.hacienda.gob.do/ministerio-de-hacienda-garantiza-a-partir-de-hoy-pagos-de-primera-quincena-de-fase/ Organización para la Cooperación y Desarrollo Económico. (2014). OCDE, Cómo abordar los desafíos fiscales de la Economía Digital. 